\title{
Efficacy, quality of life, and safety of methotrexate versus interferon in head-to-head treatment in advanced stages of mycosis fungoides and Sezary syndrome. Prospective trial (NCT02323659)
}

\author{
Ewa Chmielowska ${ }^{1,2,3}$, Małgorzata Sokołowska-Wojdyło 3,4 , Berenika Olszewska4, Maciej Studziński \\ Aleksandra Grzanka-Gadzińska ${ }^{3,6}$, Monika Zabłotna $^{4}$, Karolina Olek-Hrab ${ }^{7}$, Tomasz Iwanowski ${ }^{8}$, Monika Olejniczak ${ }^{1,2}$,
} Anna Krause ${ }^{1,2}$, Sebastian Giebel ${ }^{3,9}$

\author{
${ }^{1}$ Bydgoszcz Cancer Centre, Bydgoszcz, Poland \\ ${ }^{2}$ Centre for Diagnostics and Oncology Therapy, Tomaszow Mazowiecki, Poland \\ ${ }^{3}$ Polish Lymphoma Research Group (PLRG) \\ ${ }^{4}$ Department of Dermatology, Venerology and Allergology, Faculty of Medicine, Medical University of Gdansk, Gdansk, Poland \\ 5Hospital "Elbląska" Luxmed, Warsaw, Poland \\ ${ }^{6}$ Nicolaus Copernicus University in Torun, Ludwik Rydygier Medical College in Bydgoszcz, Poland \\ ${ }^{7}$ Department of Dermatology, Sexually Transmitted Diseases and Immunodermatology, Poznan University of Medical Sciences, Poznan, \\ Poland \\ ${ }^{8}$ Dermedica, Gdynia, Poland \\ ${ }^{9}$ Department of Bone Marrow Transplantation and Oncohaematology, Maria Skłodowska-Curie Memorial Cancer Centre and Institute \\ of Oncology, Gliwice, Poland \\ Adv Dermatol Allergol 2021; XXXVIII (2): 295-301 \\ DOI: https://doi.org/10.5114/ada.2021.106206
}

\begin{abstract}
Introduction: ESMO guidelines recommend interferon (IFN) and methotrexate (MTX) as first-line systemic therapies in mycosis fungoides (MF) and Sezary syndrome (SS).

Aim: A prospective, head-to-head trial comparing the efficacy and safety of INF- $\alpha$ and MTX as first-line treatment in MF/SS patients.

Material and methods: Forty-three patients were enrolled in the trial. The response to treatment and side effects were assessed. Study variables included mSWAT, DLQI, and VAS scores.

Results: The response rate in stage IV including SS was significantly higher in the IFN- $\alpha$ group than in the MTX group ( $100 \%$ vs. $40 \% ; p=0.03$, respectively). No significant differences were found in response rate in stage IIB and III between treatment groups. Patients treated with IFN- $\alpha$ had significantly shorter time to achieve response (TTR). Significantly fewer in the IFN- $\alpha$ group experienced adverse events (AE) in comparison to patients treated with MTX ( $81 \%$ vs. $45 \% ; p=0.02)$. There was no statistically significant difference between both groups in terms of time to progression (TTP), progression-free survival (PFS), time on treatment (ToT), and time to next treatment (TTNT). The improvement in quality of life and reduction of pruritus was comparable in both treatment groups.

Conclusions: The obtained data suggest that the efficacy of IFN- $\alpha$ as first-line treatment in advanced stage (IV) MF and SS is significantly better than MTX. IFN- $\alpha$ presented significantly better safety and tolerability and shorter TTR than MTX. However, the results should be interpreted with caution due to scarce study groups.
\end{abstract}

Key words: methotrexate, interferon, cutaneous T-cell lymphoma, efficacy.

\section{Introduction}

Cutaneous T-cell lymphomas (CTCLS) comprise a clinically heterogeneous group of extranodal non-Hodgkin lym- phomas, with mycosis fungoides (MF) and Sezary syndrome (SS) as the most common types [1, 2]. MF primarily affect the skin, but ultimately also lymph nodes, blood, and visceral

Address for correspondence: Berenika Olszewska, Department of Dermatology, Venerology and Allergology, Medical University of Gdansk, 17 Mariana Smoluchowskiego St, 80-214 Gdansk, Poland, phone: +48 5858440 10, e-mail: berenika.olszewska@o2.pl Received: 7.09.2020, accepted: 15.09.2020. 
organs may become involved. SS is an aggressive variant of CTCL with poor prognosis [1, 2]. MF is an incurable disease with stage-dependent treatment. Early stages of MF are treated with skin-directed therapies such as topical steroids and phototherapy (psoralen photochemotherapy (PUVA) or narrow-band UVB radiation) [3]. SS and advanced stages of $M F$ require systemic treatment including interferon $\alpha$ (IFN- $\alpha$ ), methotrexate (MTX), retinoids, total skin electron beam therapy, extracorporeal photopheresis, stem cell transplantation, or chemotherapy [3]. MTX and IFN- $\alpha$ seem to be effective as first-line systemic treatment in patients who are refractory to skin-directed therapies. MF and SS are rare diseases, in which adequate and well-controlled trials are difficult to perform due to small patient populations.

There are 3 major types of IFN: IFN- $\alpha$, IFN- $\beta$, and IFN- $\gamma$; however, only INF- $\alpha$ has been approved and is commonly used in the treatment of MF/SS [4]. INF- $\alpha$ has been administered in various doses and treatment regimens, usually starting with 3 million units (MIU) 3 times weekly with therapy adjustment based on clinical response [3]. The major side effects of IFN- $\alpha$ treatment are dose-dependent and include flu-like symptoms, elevated transaminases, myelosuppression, and depression. INF- $\alpha$ has proven to be effective in MF and SS treatment, both as monotherapy and in combination with oral retinoids, bexarotene, or PUVA therapy [4-12]. The few studies assessing the use of IFN- $\alpha$ monotherapy in CTCL demonstrated that partial response was achieved in $25 \%$ to $49 \%$ of patients [10-12]. A recent retrospective study by Wain et al. demonstrated that IFN- $\alpha$ therapy was associated with a better response and a shorter time to response (TTR) compared with MTX in MF patients [9].

MTX is a cytotoxic antifolate drug used in CTCL treatment in low doses once weekly, both as monotherapy and in combination with IFN- $\alpha$ or bexarotene [3]. The clinical efficacy of MTX therapy has been demonstrated with reported response rates (RR) ranging from 33\% to $71 \%$ [8, 13-15]. MTX is usually well tolerated and safe when the treatment is properly monitored. The most frequent side effects include liver function abnormalities, bone marrow suppression, and gastrointestinal toxicity [3]. Moreover, MTX is a teratogen, so women of childbearing potential are required to use contraception during and after MTX therapy. Even though MTX and IFN- $\alpha$ are commonly used in CTCL treatment, to our knowledge there are no prospective studies and only 1 retrospective study evaluating the efficacy and safety of systemic MTX vs. IFN- $\alpha$ in MF [8].

\section{Aim}

A head-to-head comparison of IFN- $\alpha$ versus MTX could provide useful information on the superiority of any of these therapies over the other in CTCL, because such conclusions have rarely been reported. Therefore, we conducted a prospective study comparing the following head to head: efficacy, safety, quality of life, and tolerance of MTX and IFN- $\alpha$ used as first-line treatment in MF and SS (ClinicalTrials.gov Identifier: NCT02323659). The patients were randomised in a $1: 1$ ratio.

\section{Material and methods}

Patients diagnosed with MF and SS treated at the Department of Dermatology, University of Medical Sciences in Poznan, Bydgoszcz Cancer Centre, the Department of Dermatology, Sexually Transmitted Diseases, and Immunodermatology of the Antoni Jurasz University Hospital No. 1 in Bydgoszcz between June 2014 and October 2017 were screened for the study. Forty-three consecutive patients with histologically confirmed MF in stage IIA to IV or SS, refractory to previous topical treatment or phototherapy, were enrolled. Disease stage was assessed according to the International Society for Cutaneous Lymphomas (ISCL) and the European Organization for Research and Treatment of Cancer (EORTC) staging systems [16]. Eligible patients with stage IIA-IV were over 18 years old, had insufficient response to topical treatment and/or phototherapy, and were naïve to systemic therapy. Patients who did not meet the eligibility criteria and those with contraindications for MTX or IFN- $\alpha$ treatment were excluded. No concomitant systemic therapy was allowed during the trial period. Informed consent was obtained from all patients. The severity of disease and response to treatment were assessed with mSWAT. The quality of life and severity of pruritus were assessed with the DLQI questionnaire and VAS scale, respectively. A detailed history was recorded, and a general physical examination was performed before the start of therapy. Baseline investigations in all patients included complete blood counts, liver function tests (ALT, AST), C-reactive protein (CRP), lactate dehydrogenase (LDH), $\beta 2$-microglobulin, and flow cytometry. While patients were on the treatment, blood tests, complete physical examinations, mSWAT, DLQI, and VAS scoring were repeated every month. Time to response, any adverse events, and treatment tolerability were recorded. Clinical endpoints and response criteria used in this study were adapted from the consensus guidelines of ISCL, the United States Cutaneous Lymphoma Consortium (USCLC), and EORTC [17]. The study was approved by the Bioethics Committee of Nicolaus Copernicus University functioning at Collegium Medicum in Bydgoszcz (KBE515/2014) and was conducted according to the principles of the Declaration of Helsinki.

Patients who met the eligibility criteria were randomized $(1: 1)$ to receive either IFN- $\alpha$ or MTX. IFN- $\alpha$ was administered subcutaneously at a dose of 3 MIU, 3 times a week. MTX was administered orally in a weekly divided dose of $20 \mathrm{mg}$, with supplementation of $15 \mathrm{mg}$ folic acid on the day after administration of MTX. The study treatment was continued until disease progression, unacceptable toxicity, or the patient's withdrawal of consent. 


\section{Statistical analysis}

Statistical calculations were performed using Statistica version 12.0 (StatSoft, Inc., 2015). Analyses of qualitative features were based on $\chi^{2}$ test using the Pearson method or the Fisher test. Independent variables that met the assumptions for parametric tests were analysed using Student's t-test. Independent variables that did not meet the parametric test assumptions were analysed using non-parametric tests (ANOVA equivalents): MannWhitney U-test (a comparison of two samples) or Kruskal-Wallis test (a comparison of multiple samples). Odds ratios (ORs) with 95\% confidence intervals were determined by logistic regression. A $p$-value of $<0.05$ was considered statistically significant. Time to event outcomes such as time to progression and time on treatment were calculated using a Kaplan-Meier estimator, and comparison between groups was assessed by log-rank test.

\section{Results}

\section{Patients}

The patients were screened between June 2014 and October 2017, and 43 of them with histologically confirmed MF and SS were randomized. Twenty-one patients were included in the IFN- $\alpha$ group, and 22 in the MTX group. The mean age of patients was $60.05 \pm 11.12$ years (median: 62.0; range: $34-78$ ) in the IFN- $\alpha$ group and $60.64 \pm 13.29$ years (median: 62.5; range: $32-82$ ) in the MTX group. The groups were comparable in terms of CTCL stage. A summary of patient characteristics is shown in Table 1.

\section{Response rate}

The overall response rate for both treatment groups was $84 \%$. The improvement rate was comparable in the IFN- $\alpha$ group (86\%) compared to the MTX group (82\%). No significant differences were observed between the IFN- $\alpha$ group and the MTX group in terms of number of patients achieving complete remission, partial remission, and refractory to treatment $(p>0.05)$.

The RR varied between the 2 treatment groups within different stages of disease (Table 2). The RR in stage IV was significantly better in the IFN- $\alpha$ group compared to the MTX group (100\% vs. $40 \%$; $p=0.03)$. The RR in the IFN- $\alpha$ group within stages IIB and IV was higher, although not significantly, than in stage IIIB (100\% vs. 50\%; $p=$ 0.09). There was no significant difference in the RR in MF stage IIIB between MTX-treated patients and those receiving IFN- $\alpha$ ( $83 \%$ vs. $50 \%$; $p=0.33$ ). The RR in the MTX group was better, but not significantly, in stage III than IV (83\% vs. $40 \% ; p=0.2)$. The RR in MF stage II did not differ between treatment groups and was equally high (100\% vs. $100 \%$ ).

The mean time needed to achieve disease response significantly differed between the groups (1.12 \pm 0.33 months; median: 1.0 , and $1.7 \pm 0.59$; median 2.0 in the
INF- $\alpha$ and MTX groups, respectively; $p=0.002$ ). Initial response was achieved earlier in the IFN- $\alpha$ group than in the MTX group. Significantly more patients achieved initial response during the first month of treatment in the IFN- $\alpha$ group (71\%) than in the MTX group (27\%) (OR = $6.67 ; 1.76-25.28 ; p=0.005)$. Disease severity decreased from baseline in both groups, resulting in a reduction in mean mSWAT score in the INF $\alpha$ group $(52.43 \pm 27.45)$ and in the MTX group (46.41 \pm 29.59$)$. However, the mSWAT score change did not differ significantly between the 2 treatment groups during the therapy $(p=0.34)$.

\section{Quality of life and pruritus assessment}

No significant differences between the groups were found in terms of DLQI score $(p=0.78)$. The mean reduction in DLQI score was $11.94 \pm 5.24$ in the IFN- $\alpha$ group and $12.8 \pm 8.08$ in the MTX group. There were no significant differences in the reduction of pruritus intensity between the 2 groups $(p=0.42)$. The mean reduction in the itch severity score was $7.05 \pm 2.65$ in the IFN- $\alpha$ group and $6.5 \pm 2.87$ in the MTX group.

\section{Adverse events and treatment tolerability}

Significantly more patients in the IFN- $\alpha$ group did not experience any adverse events (AE) in comparison to patients treated with MTX ( $81 \%$ vs. $45 \%$; OR $=4.8,1.21-$ $19.08, p=0.02$ ). No significant differences between the

Table 1. Patients' characteristics

\begin{tabular}{|c|c|c|}
\hline Characteristic & $\begin{array}{l}\text { IFN- } \alpha \text { group } \\
\text { (A) } n=21\end{array}$ & $\begin{array}{l}\text { MTX group } \\
\text { (B) } n=22\end{array}$ \\
\hline Age [years] (range) & $\begin{array}{c}60.04 \pm 11.12 \\
(34-78)\end{array}$ & $\begin{array}{c}60.63 \pm 13.28 \\
\quad(32-82)\end{array}$ \\
\hline \multicolumn{3}{|l|}{ Sex: } \\
\hline Male & 11 & 10 \\
\hline Female & 10 & 12 \\
\hline \multicolumn{3}{|l|}{ Stage at enrolment: } \\
\hline$\| A$ & 1 & 2 \\
\hline II B & 7 & 9 \\
\hline III A & 1 & 0 \\
\hline III B & 4 & 6 \\
\hline IV A1* (Sezary syndrome) & 8 & 5 \\
\hline \multicolumn{3}{|l|}{ Disease characteristics: } \\
\hline $\begin{array}{l}\text { Baseline SWAT score, mean } \\
\text { (median) }\end{array}$ & $81.57(85 \%)$ & $78.5(80 \%)$ \\
\hline Baseline DLQI score & $21.76(21)$ & $22.22(20.5)$ \\
\hline \multicolumn{3}{|l|}{ Previous therapies: } \\
\hline PUVA + topical treatment & 19 & 19 \\
\hline Topical treatment & 2 & 3 \\
\hline
\end{tabular}

*Stage IV A - T(3-4) N(O-2) M (0-1)B2 (criteria from flow cytometry) - Sezary syndrome. 
E. Chmielowska, M. Sokołowska-Wojdyło, B. Olszewska, M. Studziński, A. Grzanka-Gadzińska, M.Zabłotna, K. Olek-Hrab, T. Iwanowski, M. Olejniczak, A. Krause, S. Giebel

Table 2. Response and progression rates by disease stage

\begin{tabular}{|c|c|c|c|c|c|c|c|c|c|}
\hline \multirow[t]{2}{*}{ Variable } & \multicolumn{3}{|c|}{ IFN- $\alpha$ group $n=21$} & \multicolumn{3}{|c|}{$\operatorname{MTX} n=22$} & \multicolumn{3}{|c|}{ IFN- $\alpha /$ MTX } \\
\hline & $\begin{array}{l}\text { Response, } \\
n(\%)\end{array}$ & $\begin{array}{l}\text { TTR, mean } \\
\text { [months] }\end{array}$ & $\begin{array}{l}\text { ToT, mean } \\
\text { [months] }\end{array}$ & $\begin{array}{l}\text { Response, } \\
n(\%)\end{array}$ & $\begin{array}{l}\text { TTR, mean } \\
\text { [months] }\end{array}$ & $\begin{array}{l}\text { ToT, mean } \\
\text { [months] }\end{array}$ & $\begin{array}{l}\text { Response, } \\
p\end{array}$ & $\begin{array}{c}\mathrm{TTR} \\
p\end{array}$ & $\begin{array}{c}\text { ToT, } \\
p\end{array}$ \\
\hline \multicolumn{10}{|l|}{ Stage: } \\
\hline IIA & $1 / 1(100)$ & 1.0 & - & 2/2 (100) & 1.0 & 21.0 & 1 & 1 & - \\
\hline IIB & 7/7 (100) & 1.14 & 13.02 & 9/9 (100) & 1.5 & 7.9 & 1 & 0.18 & 0.85 \\
\hline IIIA & $0 / 1$ & 1 & 4.96 & - & 2.2 & 7.45 & - & 0.05 & 0.33 \\
\hline IIIB & $2 / 4(50)$ & & & $5 / 6(83)$ & & & 0.33 & & \\
\hline IVA & 8/8 (100) & 1.14 & 8.77 & $2 / 5(40)$ & 2 & 3.53 & 0.03 & 0.05 & 0.11 \\
\hline Progression: & & 8 & & & 5 & & & 0.27 & \\
\hline IIA & & - & & & 1 & & & & \\
\hline IIB & & 3 & & & 1 & & & & \\
\hline IIIA & & 1 & & & - & & & & \\
\hline IIIB & & 2 & & & 1 & & & & \\
\hline IVA & & 2 & & & 2 & & & & \\
\hline \multicolumn{10}{|c|}{ Quality of life and mSWAT assessment: } \\
\hline $\begin{array}{l}\text { Change in mSWAT score, } \\
\text { mean (median) }\end{array}$ & & $52.43(59)$ & & & $46.41(59)$ & & & 0.34 & \\
\hline Change in DLQI score & & 11.94 & & & 12.8 & & & 0.78 & \\
\hline \multicolumn{10}{|c|}{ Reasons for treatment discontinuation other than progressive disease: } \\
\hline Consent withdrawal & & 5 & & & 3 & & & & \\
\hline Other & & 1 & & & 0 & & & & \\
\hline
\end{tabular}

- time to response, TOT - time on treatment.

2 groups were found in the severity of adverse events reported (AE1, $p=0.72 ; \mathrm{AE} 2, p=0.1 ; \mathrm{AE} 3, p=0.19)$. Follow-up of AEs showed that liver disorders (including abnormal liver function tests, liver toxicity, cirrhosis) were

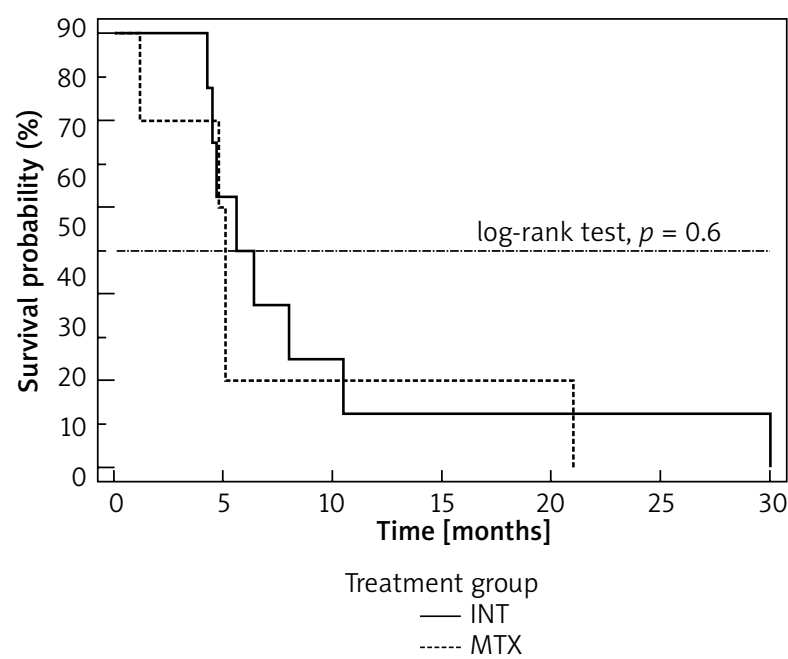

Figure 1. The Kaplan-Meier estimates of time to progression between MTX and IFN- $\alpha$ treatment groups. Long-rank test $p=0.6$. Kaplan-Meier estimate suggests that response to IFNa treatment may have a long-lasting effect significantly more frequent than other AEs (e.g. myalgia, arthralgia, osteoporosis, visual disturbances) $(p=0.01)$. Moreover, significantly more patients in the MTX group than in the IFN- $\alpha$ group had elevated liver function tests (LFTs) (27\% vs. 0\%, respectively).

Abnormal laboratory tests were present in $71 \%$ of patients treated with IFN- $\alpha$ and $67 \%$ of those treated with MTX. However, there were no significant differences between the groups in terms of frequency of laboratory test abnormalities other than LFTs (CRP, LDH, $\beta 2$ microglobulin, complete blood counts).

There was a statistically significant difference in treatment tolerability $(\mathrm{OR}=10.8,2.0-58.23, p=0.006)$; poor tolerability was noted more often in the MTX group (55\%) than the IFN- $\alpha$ group (10\%). Good tolerability of IFN- $\alpha$ treatment was reported by $90 \%$ of patients.

\section{Disease progression}

Disease progression was more frequent, although not significantly, in the IFN- $\alpha$ group compared to the MTX group; it occurred in 8 out of 21 patients (38\%) and 5 out of 22 patients $(23 \%)$, respectively $(p=0.27)$. Three patients in stage IIB, 3 in stage III, and 2 in stage IVA1 progressed on IFN- $\alpha$ treatment. In the MTX group, progression occurred in stages IIA, IIB, IIIB, and in 2 patients with stage IVA1 
disease. Detailed information on patients with progression is summarized in Table 2. CRP and white blood count were the most common abnormalities that accompanied progression in the IFN group. Overall medium TTP (for both treatment groups) was 5.1 months (95\% confidence interval, CI for median: $4.5-8)$. Median TTP for the IFN- $\alpha$ group was 5.6 months ( $95 \% \mathrm{Cl}$ for median: 4.3 to 10.5 ). Median TTP for the MTX-group was 5.1 months $(95 \% \mathrm{Cl}$ for median: 1.2 to 21) There was no statistically significant difference between both groups in terms of TTP in logrank test; $p=0.6$. The Kaplan- Meier estimate of the TTP is presented in Figure 1. Median ToT for the IFN- $\alpha$ group was 8.93 months vs. 10.52 months for the MTX group. There was no statistically significant difference between both groups in terms of progression-free survival (PFS) in log-rank test; $p=0.76$. There was also no statistically significant difference in time to next treatment data (Table 3). The second most frequent cause for discontinuation (after disease progression) in both the MTX and IFN- $\alpha$ groups was consent withdrawal, and further causes of discontinuation included adverse events, side effects, and death. There were no cases of treatment-related deaths. One patient treated with IFN- $\alpha$ died during the clinical trial due to cardiac failure. Four patients ( 1 in the IFN- $\alpha$ group and 3 in the MTX group) died during post-treatment follow-up. All deceased patients treated with MTX did not achieve treatment response, and 2 of them had disease progression. The patient in the IFN- $\alpha$ group achieved an initial response to the treatment, but later discontinued treatment due to disease progression and died.

\section{Discussion}

MF and SS treatment is challenging because there is no simple algorithm of therapeutic strategies. According to current ESMO Clinical Practice Guidelines [18], IFN- $\alpha$ seems to be preferred over MTX in MF/SS treatment. IFN- $\alpha$ has been recommended for MF treatment ranging from stage IA to stage III, especially when skin lesions are more extensive or refractory to skin-directed therapies, while low-dose MTX is usually administered in more advanced stages, particularly in stage III [18]. Both IFN- $\alpha$ and MTX are recommended as first-line treatment of SS [18]. Many therapies suggested by the guidelines, including histone deacetylase inhibitors, monoclonal antibodies, retinoids, skin-directed therapies, as well as novel agents, are unavailable or access to them is limited in many countries. Both MTX and IFN- $\alpha$ are widely available because they are relatively inexpensive and commonly used in many other diseases. However, there is a lack of clinical trials comparing the efficacy and safety of those agents in CTCL treatment. Most of the treatment recommendations are based on retrospective studies and expert opinions; therefore, every clinical trial can contribute to the determination of rational treatment strategies for lymphomas.
Table 3. Time to next treatment data

\begin{tabular}{|c|c|c|}
\hline Parameter & \multicolumn{2}{|c|}{ All patients (both arms, all stages) } \\
\hline Mean & \multicolumn{2}{|c|}{9.209} \\
\hline SE & \multicolumn{2}{|c|}{1.178} \\
\hline $95 \% \mathrm{Cl}$ for the mean & \multicolumn{2}{|c|}{6.901 to 11.518} \\
\hline Median & \multicolumn{2}{|c|}{11} \\
\hline $95 \% \mathrm{Cl}$ for the median & \multicolumn{2}{|c|}{5.000 to 12.000} \\
\hline Parameter & IFN- $\alpha$ (all stages) & MTX (all stages) \\
\hline Mean & 9 & 12.273 \\
\hline SE & 1.348 & 1.379 \\
\hline $95 \% \mathrm{Cl}$ for the mean & 6.357 to 11.643 & 9.570 to 14.976 \\
\hline Median & 11 & 15 \\
\hline 95\% Cl for the median & 5.000 to 12.000 & - \\
\hline$P$-value & \multicolumn{2}{|c|}{0.9037} \\
\hline Parameter & IFN- $\alpha$ (stage II) & MTX (stage II) \\
\hline Mean & 11.5 & 13.636 \\
\hline SE & 0.5 & 1.839 \\
\hline $95 \% \mathrm{Cl}$ for the mean & 10.520 to 12.480 & 10.032 to 17.240 \\
\hline Median & 12 & 15 \\
\hline $95 \% \mathrm{Cl}$ for the median & - & - \\
\hline$P$-value & \multicolumn{2}{|c|}{0.6619} \\
\hline Parameter & IFN- $\alpha$ (stage III) & MTX (stage III) \\
\hline Mean & 5.1 & 0 \\
\hline SE & 2.475 & 0 \\
\hline $95 \% \mathrm{Cl}$ for the mean & 0.250 to 9.950 & 0.000 to 0.000 \\
\hline Median & 6 & - \\
\hline $95 \% \mathrm{Cl}$ for the median & 0.000 to 11.000 & - \\
\hline$P$-value & \multicolumn{2}{|c|}{0.5442} \\
\hline Parameter & IFN- $\alpha$ (stage IV) & MTX (stage IV) \\
\hline Mean & 9.188 & 0 \\
\hline SE & 4.431 & 0 \\
\hline $95 \% \mathrm{Cl}$ for the mean & 0.503 to 17.872 & 0.000 to 0.000 \\
\hline Median & 5 & - \\
\hline $95 \% \mathrm{Cl}$ for the median & 0.000 to 16.000 & - \\
\hline$P$-value & \multicolumn{2}{|c|}{0.3691} \\
\hline
\end{tabular}

In our study, we analysed head to head 2 frequently used systemic therapies in MF and SS as first-line treatment. Due to the small population size, cautious interpretation of the data is required. We found that both IFN- $\alpha$ and MTX were effective in MF and SS treatment, with a slightly better response in the IFN- $\alpha$ group ( $86 \%$ vs. $82 \%$, respectively). This is consistent with a number of studies reporting on the beneficial effects of IFN- $\alpha$ in the treatment of CTCL. The RR to IFN- $\alpha$ varied between 33\% and $87 \%$, depending on the study $[8,13,19]$. IFN seems to be efficient not only as a systemic but also as a topical 
therapy. A recent study by Hu et al. showed successful management of MF lesions with intralesional injections of low-dose recombinant IFN- $\alpha 2$, which was free of generalised side effects [20]. Topical MTX also turned out to be efficient in early-stage MF, indicating that systemic drugs may represent new therapeutic options for topical treatment [21, 22].

Concerning systemic MTX, our trial showed that RR was much higher (82\%) than reported in other trials with low-dose MTX, ranging from 33 to $58 \%$ [8, 14, 19, 23]. An even higher response to treatment was observed in the study by Aviles et al., in which combination therapy with both MTX and IFN- $\alpha$ was associated with a complete RR of $74 \%$ [23]. Concerning RR, it should be stressed that both study groups were relatively small, which might be the reason for such high RR in both therapies.

Zackheim et al. demonstrated that MTX-treated patients with erythrodermic MF had a better RR compared to patch/plaque MF (58\% vs. 33\%) [14]. We also observed differences in MF and SS response to MTX and IFN- $\alpha$ within the different stages of the disease. Our results indicate that both MTX and IFN- $\alpha$ are equally efficient in tumour stage IIB. Moreover, MTX appears to be a slightly better treatment option than IFN- $\alpha$ in the erythrodermic stage of MF, which is consistent with the study by Zackheim et al. [14]. Because of a lack of statistical difference, none of the therapies can be unreservedly treated as a better treatment option than the other in the erythrodermic stage of MF. On the other hand, patients with advanced MF stage IV and SS treated with IFN- $\alpha$ presented significantly better RR than those in the MTX group (100\% vs. 40\%). This suggests that IFN- $\alpha$ is more effective in the advanced stage of MF compared to MTX; however, the obtained data should be interpreted with caution due to scarce study groups. It would be of great value to perform studies including larger and more diverse study groups.

We also did not observe any difference in the overall reduction in mSWAT score between the 2 groups, perhaps due to the relatively small study groups. There was no statistically significant difference between both groups in terms of TTP, PFS, ToT, and TTNT. Interestingly, the TTR was significantly shorter in the IFN- $\alpha$ group than in the MTX group (1 month vs. 2 months). Responses to both IFN- $\alpha$ and MTX were achieved 1 month earlier compared to the results published by Wain et al. [9]. The reasons for differences in TTR and RR between our trial and the Wain et al. study are unclear [9]. Interestingly, $90 \%$ of our patients were previously treated with topical agents and psoralen plus ultraviolet A (PUVA) therapy, albeit without success. It is possible that photochemotherapy, by its immunosuppressive and apoptotic effects, had facilitated subsequent IFN- $\alpha$ and MTX activity.

Adverse events were more frequent in the MTX group than in the IFN- $\alpha$ group, which is contrary to the results of Wain et al. However, only 1 patient treated with MTX discontinued treatment due to symptoms of cirrhosis. Laboratory test abnormalities were slightly more frequent in the IFN- $\alpha$ group than in the MTX group, but they did not influence patient tolerability assessments. Overall, the tolerability of IFN- $\alpha$ was much better compared to MTX. Our results are comparable to those of Wain et al., suggesting that side effects of MTX impair treatment evaluation to a greater extent than in the case of IFN- $\alpha$ [9]. The improvement in quality of life (DLQI score) was similar in both groups during our trial. Moreover, both drugs similarly reduced itching.

To our best knowledge, this is the first prospective randomized study comparing the efficacy of MTX and IFN- $\alpha$ in MF and SS as first-line treatment. The majority of our observations are supported by the results of the retrospective study by Wain et al. [9]. In conclusion, despite the limitations of a small sample size, the presented data indicate that IFN- $\alpha$ seems to be superior to MTX in terms of safety, tolerability, and time to achieve response to treatment. Considering RR, the efficacy of the 2 drugs is comparable in tumour stage MF and significantly better for IFN- $\alpha$ in advanced stage IV of MF/SS. MTX is a cost-effective and relatively efficient drug, and it should be considered as a second-line treatment or a first choice in cases of contraindication to IFN- $\alpha$ therapy. Due to various side effects and the TTR, both drugs should be used after considering the patient's comorbidities, medication, and individual needs.

\section{Conflict of interest}

The authors declare no conflict of interest.

\section{References}

1. Willemze R, Jaffe ES, Burg G, et al. WHO-EORTC classification for cutaneous lymphomas. Blood 2005; 105: 3768-85.

2. Swerdlow SH, Campo E, Harris NL, et al. WHO Classification of Tumors of Haematopoietic and Lymphoid Tissues. Revised $4^{\text {th }}$ Edition. IARC, Lyon 2017.

3. Trautinger F, Eder J, Assaf C, et al. European Organization for Research and Treatment of Cancer consensus recommendations for the treatment of mycosis fungoides/Sézary syndrome - update 2017. Eur J Cancer 2017; 77: 57-74.

4. Olsen EA. Interferon in the treatment of cutaneous T-cell lymphoma. Dermatol Ther 2003; 16: 311-32.

5. Olsen EA, Whittaker S, Kim YH, et al. Clinical end points and response criteria in mycosis fungoides and Sézary syndrome: a consensus statement of the International Society for Cutaneous Lymphomas, the United States Cutaneous Lymphoma Con-sortium, and the Cutaneous Lymphoma Task Force of the European Organisation for Research and Treatment of Cancer. J Clin Oncol 2011; 29: 2598-607.

6. Jumbou O, N'Guyen JM, Tessier MH. Long-term follow-up in 51 patients with mycosis fungoides and Sézary syndrome treated by interferon-alfa. Br J Dermatol 1999; 140: 427-31.

7. McGinnis KS, Junkins-Hopkins JM, Crawford G, et al. Lowdose oral bexarotene in combination with low-dose interferon alfa in the treatment of cutaneous T-cell lymphoma: 
clinical synergism and possible immunologic mechanisms. J Am Acad Dermatol 2004; 50: 375-9.

8. Rupoli S, Goteri G, Pulini S, et al. Long-term experience with low-dose interferon-alpha and PUVA in the management of early mycosis fungoides. Eur J Haematol 2005; 75: 136-45.

9. Wain T, Pavli A, Wells J, Fernandez-Peńas P. The efficacy and safety of methotrexate versus interferon in cutaneous T-cell lymphomas. J Dermatolog Treat 2018; 29: 715-9.

10. Olsen EA, Rosen ST, Vollmer RT, et al. Interferon alfa-2a in the treatment of cutaneous T cell lymphoma. J Am Acad Dermatol 1989; 20: 395-407.

11. Bunn PA Jr, Foon KA, Ihde DC, et al. Recombinant leukocyte A interferon: an active agent in advanced cutaneous T-cell lymphomas. Ann Intern Med 1984; 101: 484-7.

12. Kohn EC, Steis RG, Sausville EA, et al. Phase II trial of intermittent high-dose recombinant interferon alfa-2a in mycosis fungoides and the Sézary syndrome. J Clin Oncol 1990; 8: 155-60.

13. Papa G, Tura S, Mandelli F, et al. Is interferon alpha in cutaneous T-cell lymphoma a treatment of choice? Br J Haematol 1991; 79: 48-51.

14. Zackheim HS, Kashani-Sabet M, Hwang ST. Low-dose methotrexate to treat erythrodermic cutaneous T-cell lymphoma: results in twenty-nine patients. J Am Acad Dermatol 1996; 34: 626-31.

15. Zackheim HS, Kashani-Sabet M, McMillan A. Low-dose methotrexate to treat mycosis fungoides: a retrospective study in 69 patients. J Am Acad Dermatol 2003; 49: 873-8.

16. Olek-Hrab K, Maj J, Chmielowska E, et al. Methotrexate in the treatment of mycosis fungoides - a multicenter observational study in 79 patients. Eur Rev Med Pharmacol Sci 2018; 22: 3586-94.

17. Olsen E, Vonderheid E, Pimpinelli N, et al. Revisions to the staging and classification of mycosis fungoides and Sezary syndrome: a proposal of the International Society for Cutaneous Lymphomas (ISCL) and the cutaneous lymphoma task force of the European Organization of Research and Treatment of Cancer (EORTC). Blood 2007; 110: 1713-22.

18. Willemze R, Hodak E, Zinzani PL, et al.; ESMO Guidelines Working Group. Primary cutaneous lymphomas: ESMO Clinical Practice Guidelines for diagnosis, treatment and followup. Ann Oncol 2013; 24: vi149-54.

19. Olsen EA, Bunn PA. Interferon in the treatment of cutaneous T-cell lymphoma. Hematol Oncol Clin North Am 1995; 9: 1089-107.

20. Hu JK, Carlson K, Girardi M. Focus: skin: low-dose intralesional recombinant interferon- $\alpha 2 b$ in the treatment of mycosis fungoides. Yale J Biol Med 2020; 93: 41-4.

21. Ackara D, Bashyam AM, Pichardo RO, Feldman SR. Topical methotrexate in dermatology: a review of the literature. J Dermatol Treat 2020; 1-21. doi: 10.1080/09546634.2020.1770170.

22. Lebas E, Chapelier C, Quatresooz P, et al. Exploratory assessment of oxygen flow-assisted cutaneous administration of methotrexate for superficial basal cell carcinoma, mycosis fungoides, and extramammary paget disease. J Invest Dermatol 2020; 140: 583-92.

23. Avilés A, Nambo MJ, Neri N, et al. Interferon and low dose methotrexate improve outcome in refractory mycosis fungoides/Sézary syndrome. Cancer Biother Radiopharm 2007; 22: 836-40. 